\title{
IMAGINARIOS DE LA CORPOREIDAD: CUERPO, SILENCIOS Y TIEMPOS EN PEDRO PÁRAMO, DE JUAN RULFO
}

\author{
José Enrique Finol \\ Universidad de Lima \\ Lima, Perú \\ joseenriquefinol@gmail.com
}

RESUMEN / ABSTRACT

La presente investigación intenta determinar cuáles son los imaginarios corporales que estructuran la novela Pedro Páramo (1955), de Juan Rulfo, un texto sobre el cual se han realizado numerosos análisis para indagar sobre su concepción de la muerte. A partir de la breve definición de algunos conceptos operativos para nuestro análisis, se propone la hipótesis interpretativa según la cual el texto se estructura sobre imaginarios corporales, lo que nos permite elaborar un modelo sobre una semiótica de la mirada, del silencio y del tiempo, articuladas a los temas de una corporeidad erótica y sexual. El análisis concluye que los imaginarios corporales en Pedro Páramo deben ser leídos e interpretados en el marco de una hiperisotopía de la muerte como estructurante cardinal del texto.

Palabras clave: Pedro Páramo, cuerpo, semiótica, mirada, silencio.

\section{IMAGINARIES OF CORPOREALITY: BODY, SILENCES aNd tIMES IN PEDRo PÁRAMo, BY JUAN RULFo}

The purpose of this investigation is to establish the corporeal imaginaries that are at the roots of the Juan Rulfo's short novel Pedro Páramo (1955), a text about which many analyses have been done with the aim of establishing his death vision. After a brief definition of some operational concepts that will enable our analysis, we propose an interpretative hypothesis, according to which the novel is structured over corporal imaginaries, a fact that will allow us to elaborate a model of a semiotic glance, of silence and time, which are articulated to an erotic and sexual corporeity. Our analysis concludes that corporeal imaginaries in Pedro Páramo must be read and interpreted within the frame of a hyper isotopy of death as cardinal semiotic structurant of the text. 
KEYWords: Pedro Páramo, body, semiotics, glance, silence.

Recepción: 20/04/2018

Aprobación: 04/10/2018

Lo supe ya muy tarde, cuando el cuerpo se me habia achaparrado, cuando el espinazo se me saltó por encima de la cabeza, cuando ya no podía caminar. Diálogo de Dorotea y Juan Preciado, en Pedro Páramo, de Juan Rulfo

\section{INTRODUCCIÓN}

La presente investigación parte de la hipótesis según la cual los imaginarios corporales en la novela Pedro Páramo (1955), de Juan Rulfo (1917-1986), son estructurantes fundamentales en la organización y significado del relato. En tal sentido, vamos a hacer un análisis de las diversas formas en que el cuerpo -ojos, manos, hombros, rostro, etc-- se constituye en isotopías dominantes para la articulación de significados fundamentales en la narrativa de la novela. La metodología está basada en la propuesta sobre la semiotización del mundo que hemos denominado Corposfera (Finol 2015), la cual aborda los procesos de significación y comunicación del cuerpo en el marco de diferentes contextos.

Después de revisar algunos de los muchos autores que se han ocupado de Pedro Páramo, vamos a proponer algunos conceptos que nos parecen heurísticamente rentables para el análisis de la obra. A partir de allí, analizaremos cuatro temas fundamentales que hemos denominado semiótica de la mirada, semiótica de las voces y del silencio, cuerpo sexualidad y deseo y, finalmente, hablaremos de la estructura del tiempo en la novela. Todos los temas giran en torno a los imaginarios corporales que, junto a la visión de la muerte, articulan la estructura narrativa de Pedro Páramo. 


\title{
CORPOREIDAD Y MUERTE
}

\begin{abstract}
Me sentí en un mundo lejano y me dejé arrastrar. Mi cuerpo, que parecía aflojarse, se doblaba ante todo, había soltado sus amarras y cualquiera podía jugar con él como si fuera de trapo.
\end{abstract}

Juan Preciado en Pedro Páramo (201)

Como veremos, las isotopías corporales que dominan la novela forman parte de lo que llamaremos la hiperisotopía de la muerte, parte fundamental de un imaginario que permea todo el texto y que, desde su inicio, se expresa en la muerte de Dolores Preciado, la madre de Juan Preciado, personaje-narrador que por petición de su progenitora va a Comala en busca de su padre. La hiperisotopía de la muerte ha sido analizada desde distintas ópticas y autores (entre ellos, Kent, 1976; Echavarren, 1981; Morales Ladrón, 1999; Patron, 2011; Maya Franco, 2012; García Fierro, 2014; Battersby, 2014; Origoni, 2015; Xie, 2015; Polisena, 2017; Carvalho da Silva, 2018); sin duda, toda nueva interpretación de Pedro Páramo debe tomar en cuenta ese componente fundamental que da sentido a los otros.

Solo como un indicador de la abrumadora presencia del imaginario mortuorio en Pedro Páramo, señalemos que no menos de 87 veces aparecen términos que directamente la mencionan, tanto en forma de sustantivos (muerte, muertos, cadáver, difunto, etc.), como en distintas realizaciones del verbo "morir" (mueren, murió, morir (-se, -me, -irá, -iera, etc.); además de otros verbos y expresiones (“cerrar los ojos...”, “...quieto ya su corazón”, etc.); a lo cual se suman los diálogos entre personajes fallecidos, entre ellos el propio Juan Preciado a quien las voces apagadas de los habitantes de Comala lo llevan a la muerte: "Es cierto, Dorotea. Me mataron los murmullos".

En razón de lo anterior, nos referiremos a esa hiperisotopía como un marco general, pero también como condición frecuente en la caracterización de las isotopías corporales. Al contrario de la abundancia de estudios sobre el tema de la muerte en Pedro Páramo, las isotopías corporales han sido relativamente poco analizadas. Sobre ese tema hemos encontrado trabajos de Boullosa (1998), Hannan (1999), Maldonado (2001), Saldías (2011) y García Gutiérrez (2017), que nos servirán para orientar y confrontar nuestro propio análisis. 


\section{PRECISIONES METODOLÓGICAS: ISOTOPÍAS E HIPERISOTOPÍAS, IMAGINARIOS Y SÚPER SIGNOS}

Como es conocido, el concepto de isotopía ha sido definido por Greimas y Courtés, para quienes "en lugar de designar únicamente la iteratividad de clasemas, (la isotopía) se define como la recurrencia de categorías sémicas" (197). Eco la define como "un término paraguas que cubre varios fenómenos. Como todo término paraguas este muestra que la diversidad esconde alguna unidad. En verdad, isotopía se refiere casi siempre a la constancia en una dirección que un texto exhibe cuando es sometido a las reglas de coherencia interpretativa" (201). Para Klinkenberg, por su parte, "un enunciado portador de una redundancia que asegura la homogeneidad de un sentido se llama isótopo (la palabra isotopía designa esta homogeneidad)" (150). Se trata de un concepto operatorio que permite determinar la direccionalidad de sentido de un texto o de un corpus, lo que no solo facilita las operaciones interpretativas del lector sino también las operaciones heurísticas del analista.

Lo que denominamos hiperisotopía (Finol 2015, Finol y Finol 2017) es una estructura semiótica más general, capaz de sobredeterminar las isotopías parciales de un texto o corpus. En ese sentido, para nosotros el concepto es diferente del uso que le da Matos Frías (2012); como en el caso de Pedro Páramo, la muerte permea todas las demás estructuras de significados para transformarlas en un sentido general omnipresente: la muerte que habita un pueblo donde la vida se ha escapado para siempre; un pueblo donde quienes llegan vivos, como Juan Preciado, también vienen a morir, donde los muertos dialogan entre sí.

Los imaginarios son para nosotros hipertextos, estructuras semióticas generales que permean las estructuras culturales y sociales; ellas están presentes en diversos tipos de textos y corpus, tienen representaciones y rituales propios y, desde allí, generan textos diversos. Como hemos señalado en el análisis del mito del Minotauro (Finol y Finol 2014), un hipertexto ${ }^{1}$ es un generador de otros textos, tal como ocurre con dicho mito, a partir del cual se han creado obras de teatro, cuentos, novelas y poemas, los cuales realizan y actualizan estructuras fundamentales del mismo.

"El hipertexto se definiría aquí como un mecanismo generativo de estructuras de significación propias de diversos tipos de discurso, capaz de producir re-articulaciones textuales en tiempos y espacios distintos a los de su ocurrencia original" (Finol y Finol 20). 
Los imaginarios de la muerte, como ha explicado Octavio Paz, tienen una fuerte presencia en la cultura mexicana, donde se la representa y celebra de forma ritual, festiva y multitudinaria. Al referirse a la muerte, Paz afirma que "El mexicano (...) la frecuenta, la burla, la acaricia, duerme con ella, la festeja, es uno de sus juguetes favoritos y su amor más permanente" (63), porque, finalmente, "la muerte nos venga de la vida, la desnuda de todas sus vanidades y pretensiones y la convierte en lo que es: unos huesos mondos y una mueca espantable" (64). Esos imaginarios de la muerte se manifiestan, de diversas formas, en Pedro Páramo; ellos le sirven de dinámica tela de fondo, no solo a la novela sino también a todas las prácticas, creencias y rituales de la sociedad de ese país.

Por último, proponemos la noción de súper signo, un concepto que podemos aplicar a aquellos signos particulares, específicos, cuyo significante o significado es reiterativamente utilizado en un determinado texto. Como veremos, creemos que ese concepto se aplica efectivamente a los ojos, término que Rulfo utiliza con marcada reiteración en Pedro Páramo.

Estos cuatro conceptos nos ayudarán a abordar, con mayor eficiencia heurística, el análisis e interpretación de las isotopías corporales en Pedro Páramo.

\section{ISOTOPÍAS CORPORALES EN PEDRO PÁRAMO: UNA SEMIÓTICA DE LA MIRADA}

"El aire nos hacía reir; juntaba la mirada de nuestros ojos, mientras el hilo corría entre los dedos".

Pedro Páramo a Susana San Juan (subrayado nuestro)

Para comenzar, es importante señalar que el término "cuerpo" aparece en Pedro Páramo 34 veces y a ello se suman numerosas menciones específicas de sus diferentes partes: dedos, ojos, corazón, boca, dientes, lengua, cabeza, mano, labios, piernas, hombros, pies, brazos, estómago, corazón, costillas, orejas, cara, sangre, etc. Es de particular interés el reiterativo uso del término "ojo", el cual aparece 63 veces, lo que sugiere la configuración de una semiótica de la mirada. Dicho sustantivo aparece acompañado de adjetivos, expresiones adjetivantes y frases como en los casos de "ojos reventados", 
"ojos de aguamarina", "ojos medio grises", "ojos medio amarillos", "ojos humildes", "sus ojos humildes", “ojos redondos", "ojos tristes", "ojos pequeños", "le harán remolino los ojos", "ojos tan sin mirada", "ojo roto", "ojos fríos, indiferentes", "se me torció un ojo", "sus ojos "como de dulce", "ojos cerrados", "ojos abiertos", "ojos inquietos, "ojos apretados", "la gelatina de los ojos", "La alegría de los ojos de Dios", "le apretaba los ojos", "ojos entreabiertos", "ojos colorados", "ojos azorados", "se me perdían los ojos mirándote", "sus ojos apenas se movían", "Y yo no tendré manos para taparme los ojos y no verlo".

Si intentamos una clasificación de los rasgos semánticos comunes, definitorios, de los ojos, podríamos prefigurar cómo es esa semiótica de la mirada en los personajes de la novela. En las numerosas realizaciones del término "ojos" encontramos, por ejemplo, un criterio cromático ("ojos de aguamarina", "ojos medio grises", "ojos medio amarillos", "ojos colorados"); un criterio emocional ("ojos tristes", "ojos humildes", "sus ojos humildes se endurecieron", "ojos fríos, indiferentes", "ojos azorados"); otro físico ("ojos redondos", "ojos reventados", "ojos pequeños", “ojo roto"); y otro posicional ("ojos cerrados", "ojos abiertos", "ojos entreabiertos", "le harán remolino los ojos", "se me torció un ojo", "ojos apretados", "sus ojos apenas se movían”). Como se ve, la descripción de los ojos va más allá de su función visual; para Rulfo ellos constituyen un eficaz modo de expresión y comunicación que prefigura una visión del cuerpo como un objeto productor de semiosis continuas.

Esa construcción progresiva de una semiótica de la mirada que Rulfo elabora, no se expresa solamente en la reiterativa recurrencia a esos órganos de la visión, sino que tiene sus dos polos culminantes en textos donde ellos confirman su condición de súper signos, los cuales cumplen una función determinante en la elaboración de un modelo isotópico, pues contribuyen a crear esos microuniversos semánticos que son las isotopías.

El primero de los dos polos aparece en la tercera página del libro, cuando Juan Preciado señala que ve Comala a través de los recuerdos de su madre: "Traigo los ojos con que ella miró estas cosas, porque me dio sus ojos para ver" $(194)^{2}$. Y, como se verá, el hijo no solo trae los ojos de la madre, sino que viene a Comala para, también, morir por ella, morir en su lugar, ya que 
ella no pudo hacerlo: "Mi madre, que vivió su infancia y sus mejores años en este pueblo y que ni siquiera pudo venir a morir aquí. Hasta para eso me mandó a mí en su lugar" (253). Se trata de cerrar el ciclo de la vida $\rightarrow$ muerte $\rightarrow$ otra vida en el mismo lugar donde Dolores Preciado ha debido morir pero no pudo.

El otro polo culminante de esa semiótica de la mirada también tiene que ver con Dolores Preciado, la mujer con la que Pedro Páramo se casa solo para obtener sus tierras: "-Le dirás a la Lola esto y lo otro y que la quiero. Eso es importante. De cierto, Sedano, la quiero. Por sus ojos, ¿sabes? Eso harás mañana tempranito" (226, subrayado nuestro). También Eduviges Dyada señala la hermosura de los ojos de Dolores Preciado: "Tu madre en ese tiempo era una muchachita de ojos humildes. Si algo tenía bonito tu madre, eran los ojos. Y sabían convencer" (207). Esta reiteración del término "ojos" no solo aparece en Pedro Páramo sino también en El llano en llamas, en cuyos cuentos se menciona al menos cincuenta veces.

Como puede verse, lo corporal se va constituyendo, progresiva y reiterativamente, en una hiperisotopía que acompaña a la de la muerte, con la cual interactúa de diversas maneras, lo que se observa en expresiones como "a mis manos les costó trabajo zafarse de sus manos muertas" (193), "Murió cocon (sic) una pata arriba y otra abajo" (281), "A mí me dolió mucho ese muerto -dijo Terencio Lubianes-. Todavía traigo adoloridos los hombros" (218), "Murió retorcida por la sangre que la ahogaba (220)".

\section{CUERPO Y MUERTE}

Boullosa (1998), en un trabajo que utiliza como marco referencial las caracterizaciones del cuerpo hechas por San Pablo, propone una radical distinción entre "el desorden del cuerpo y el orden de los fantasmas" (58), y define a Comala como "la tierra de los que no tienen cuerpo, porque el cuerpo es el mal" (...), donde "la corporeidad será regida por los sin-cuerpo" (55). Esa "corporeidad fantasmal" encaja bien con la hiperisotopía de la muerte que, como hemos dicho, es la columna vertebral del texto de Rulfo.

Por su parte, Hannan (1999) afirma: "That madness is the sole means of self-assertion and resistance emphasizes the limits of sexual expression for women in this realm" (441). García Gutiérrez ha desarrollado un análisis de esa locura en Pedro Páramo, en particular del personaje Susana San Juan, a partir del modelo mítico del Génesis, un modelo basado en la "representación 
bíblica de la caída de la Gracia y expulsión del Paraíso", con lo cual sigue a Freeman (1992), análisis que la lleva a proponer los conceptos de cuerpo carnal y cuerpo mítico para interpretar al personaje mencionado ${ }^{3}$. Aunque no comparto el modelo de fondo que ella propone, pues la argumentación me parece insuficiente, creo que es importante rescatar de su análisis la puesta en relieve de lo corporal en uno de los personajes de relativa importancia en la obra. Para García Gutiérrez, en efecto,

Susana San Juan (...) empieza con una impugnación inaugural: la que ejerce su cuerpo carnal contra el cuerpo mítico que le impone el cacique; pero si éste es obra de Pedro Páramo, el otro, el carnal, es obra de Rulfo que le da la voz dejando que la suya se cuele entre los murmullos del libro también (99).

Frente al cuerpo mítico, esa estratagema para su disciplinamiento social, esa coartada moral para el hombre, Susana se pone el cuerpo carnal afirmando soberanamente el principio del placer frente al sufrimiento (113).

Susana San Juan, mujer de Pedro Páramo, es un personaje cuya corporeidad está definida por dos rasgos corporales principales: la locura y la desnudez. Para varios de los personajes, Susana es "una pobrecita loca", "La última esposa de Pedro Páramo. Unos dicen que estaba loca". Ella misma se reconoce loca en su diálogo con Justina: “¿Dices que estoy loca? Está bien”, y también en conversación con su propio padre:

Bartolomé San Juan: — ¿Estás loca?

Susana San Juan: — ¿No lo sabías?

Bartolomé San Juan: — ¿Estás loca?

Susana San Juan: —Claro que sí, Bartolomé. ¿No lo sabías? (272).

La desnudez de Susana se manifiesta en dos escenarios. El primero es abierto al mundo, es la playa, donde se baña con Florencio:

3 Una aproximación crítica similar realiza Saldías al afirmar que "la novela se define sobre la base de conceptos religiosos como el pecado, el perdón, la culpa, la salvación, el purgatorio, el infierno y el paraíso" (29). 
—En el mar sólo me sé bañar desnuda —le dije. (...) El mar moja mis tobillos y se va; moja mis rodillas, mis muslos: rodea mi cintura con su brazo suave, da vuelta sobre mis senos; se abraza de mi cuello; aprieta mis hombros. Entonces me hundo en él, entera. Me entrego a él en su fuerte batir, en su suave poseer, sin dejar pedazo (283).

Hannan sugiere, incluso, una relación amatoria entre el cuerpo de Susana y ese espacio abierto: "A sense of openness pervades the interaction of woman and sea: Susana's open legs and arms parallels the vast stretch of the water towards the horizon, and her body is naked and exposed to the sand and waves. She takes in all that she can, welcoming again and again her natural lover and offering her body in return" (454).

El otro escenario es cerrado, es el cuarto de la casa, en la finca la Media Luna, donde vive en una suerte de clausura:

Ella despertó un poco antes del amanecer. Sudorosa. Tiró al suelo las pesadas cobijas y se deshizo hasta del calor de las sábanas. Entonces su cuerpo se quedó desnudo, refrescado por el viento de la madrugada. Suspiró y luego volvió a quedarse dormida.

Así fue como la encontró horas después el padre Rentería; desnuda y dormida (288. Subrayados nuestros).

Ambas condiciones, locura y desnudez, se orquestan como estrategias de diferencia y resistencia frente al dominio de Pedro Páramo; es Susana la única que se resiste y desafía al poder del cacique, a su posesión y dominio de los cuerpos femeninos y a su control y sumisión de los cuerpos masculinos. Ambas, locura y desnudez, son estrategias narrativas de resistencia y rechazo, no solo contra el todo poderoso Pedro Páramo, sino también contra su padre, Bartolomé San Juan, contra el propio padre Rentería y contra Dios mismo, a quien recrimina la muerte de Florencio: “¡Señor, tú no existes! Te pedí tu protección para él. Que me lo cuidaras. Eso te pedí. Pero tú te ocupas nada más de las almas" (288).

\section{UNA SEMIÓTICA DE LAS VOCES Y DEL SILENCIO}

"En mi vida hay muchos silencios. En mi escritura también", habría dicho Rulfo, según Susan Sontag (32). El análisis de los imaginarios corporales, nos parece, es inseparable de los imaginarios del silencio, pues esa corporeidad construida por Rulfo no se limita al cuerpo o a algunas de sus partes, sino 
también a las expresiones del mismo. Un factor importante en esa dirección son las expresiones vocales, las cuales, actuando como súper signo, configuran también un imaginario del silencio. Los actores del relato no solo hablan sino que tal expresión es una conformación detallada, minuciosa, de una suerte de imaginario del silencio, constituido por murmullos, rumores, susurros, bisbiseos, borboteos, zumbidos o por palabras "vacías de ruido", donde no hay "voces claras sino secretas", "Rumor de voces. Arrastrar de pisadas despaciosas como si cargaran con algo pesado. Ruidos vagos", "un lamento rumoroso de Sonidos".

Si bien la palabra "silencio" aparece 14 veces en el texto, mientras que la palabra "ruido" aparece en 23 ocasiones, en realidad esta última es una sobredeterminación de la primera, un recurso estilístico que se observa en expresiones como "pueblo sin ruidos", "Ruidos callados", "Como que se van las voces. Como que se pierde su ruido. Como que se ahogan. Ya nadie dice nada", "hasta que alcancé a distinguir unas palabras vacías de ruido", "ruidos vagos", "La lluvia amortigua los ruidos", "No, ruido ni hizo", "Después salió cerrando la puerta sin hacer ruido", "Se levantó del catre sin hacer ruido", etc.

En tal sentido, en Pedro Páramo el imaginario del silencio no es contrario a las voces y al ruido, sino que estos están dentro de la misma mudez del entorno, actúan como una sordina, forman "la hondura del silencio", o, como señala Bellini, "El silencio, a su manera, es un ruido, se le escucha, un ruido que sólo la muerte permite percibirlo exactamente por lo que es" (3).

Como la muerte, el imaginario del silencio permea los movimientos y las voces, cubre los espacios y el entorno, se pega a los cuerpos, a sus edades y nombres ${ }^{4}$, y arropa todas las acciones narrativas: “Al despertar, todo estaba en

\footnotetext{
García Márquez se ha referido a dos problemas esenciales para la adaptación de Pedro Páramo al cine. Uno de ellos son los nombres: "Todo nombre se parece de algún modo a quien lo lleva, y eso es mucho más notable en la ficción que en la vida real" (14). Rulfo habría dicho que "pone los nombres de sus personajes leyendo lápidas de tumbas en los cementerios de Jalisco. Lo único que se puede decir a ciencia cierta es que no hay nombres propios más propios que los de la gente de sus libros" (15). Ekstrom ha dedicado un interesante trabajo al tema de los nombres en Pedro Páramo y concluye que "His naming techniques are also important in their contribution to the tone and content of the work. He uses a rather psychological onomastic approach, with emphasis on connotations. His names are often attributive, underscoring the personality traits of his characters (p. 2). El Segundo problema señalado por García Márquez es el de las edades: "En toda su obra, Juan Rulfo ha tenido el cuidado de ser muy descuidado en cuanto a los tiempos de sus criaturas" (p. 15).
} 
silencio; sólo el caer de la polilla y el rumor del silencio. No, no era posible calcular la hondura del silencio que produjo aquel grito. Como si la tierra se hubiera vaciado de su aire. Ningún sonido; ni el del resuello, ni el del latir del corazón; como si se detuviera el mismo ruido de la conciencia" (221).

Ese mismo imaginario del silencio lo encontramos también en el cuento Luvina de El llano en llamas (1953):

Poco después del amanecer se calmó el viento. Después regresó. Pero hubo un momento en esa madrugada en que todo se quedó tranquilo, como si el cielo se hubiera juntado con la tierra, aplastando los ruidos con su peso... Se oía la respiración de los niños ya descansada. Oía el resuello de mi mujer ahí a mi lado:

—“¿Qué es? — me dijo.

——¿Qué es qué? —le pregunté.

- Eso, el ruido ese.

—-Es el silencio. Duérmete. Descansa, aunque sea un poquito, que ya va a amanecer (64, subrayados nuestros).

Una de las primeras constataciones que Juan Preciado hace al llegar a Comala tiene que ver con el silencio: "Ahora estaba aquí, en este pueblo sin ruidos", un tema al que Bellini ha dedicado un breve artículo en el cual señala que

... el silencio se nos presenta en dos dimensiones: una dramática, la expectativa de algo que va a ocurrir y que permanece misterioso, pero que ciertamente será de signo negativo; otra sentimental, privación de un dato que podríamos llamar interior, o afectivo, y que implica sorpresa, decepción, predisposición a lo peor (2).

Ese silencio que se trasmuta en rumores, murmullos y bisbiseos es también acompañante de la misma muerte. Juan Preciado vive esa muerte en los rumores del silencio: "Me mataron los murmullos"; y luego agrega: "Y cuando me encontré con los murmullos se me reventaron las cuerdas"; mientras que su madre, Dolores Preciado, desde su muerte comenta: "Allí, donde el aire cambia el color de las cosas; donde se ventila la vida como si fuera un murmullo; como si fuera un puro murmullo de la vida..." (246, subrayados nuestros).

Mientras deambula por el pueblo, Juan Preciado no hace sino confirmar lo que su madre le había dicho: 
Vi que no había nadie, aunque seguía oyendo el murmullo ${ }^{5}$ como de mucha gente en día de mercado. Un rumor parejo, sin ton ni son, parecido al que hace el viento contra las ramas de un árbol en la noche, cuando no se ven ni el árbol ni las ramas, pero se oye el murmurar. Así. Ya no di un paso más. Comencé a sentir que se me acercaba y daba vueltas a mi alrededor aquel bisbiseo apretado como un enjambre... (247, subrayados nuestros).

Más aún, los murmullos son un modo del silencio que está asociado a la muerte: "Y de las paredes parecían destilar los murmullos como si se filtraran de entre las grietas y las descarapeladuras. Yo los oía. Eran voces de gente; pero no voces claras, sino secretas, como si me murmuraran algo al pasar, o como si zumbaran contra mis oídos" (247); más aún, "Uno oye. Oye rumores; pies que raspan el suelo, que caminan, que van y vienen" (213).

Aunque ese rumor, como lo evoca Pedro Páramo al recordar a Susana, fue alguna vez rumor de vida, "Oíamos allá abajo el rumor viviente del pueblo", se trata de esa semiótica de las voces y del silencio donde habita la vidamuerte de los pobladores de Comala y de Comala mismo, un pueblo donde el cacique trata de exorcizar la muerte de su amada al ordenar un interminable repicar de campanas en todas las iglesias del pueblo: "A los tres días todos estaban sordos. Se hacía imposible hablar con aquel zumbido de que estaba lleno el aire. Pero las campanas seguían, seguían, algunas ya cascadas, con un sonar hueco como de cántaro" (303).

Esa semiótica del silencio y las voces se articula coherentemente a los ecos que habitan Comala, tal como lo señala Damiana Cisneros:

-Este pueblo está lleno de ecos. Tal parece que estuvieran cerrados en el hueco de las paredes o debajo de las piedras. Cuando caminas, sientes que te van pisando los pasos. Oyes crujidos. Risas. Unas risas ya muy viejas, como cansadas de reír. Y voces ya desgastadas por el uso. Todo eso oyes. Pienso que llegará el día en que estos sonidos se apaguen (230).

Esos ecos habitan los silencios de Comala, son parte de ellos, en cierto modo, los constituyen: "Carretas vacías, remoliendo el silencio de las calles.

5 Ruffinelli (xxxi) señala que uno de los títulos que Rulfo pensó para su novela era, justamente, Murmullos. 
Perdiéndose en el oscuro camino de la noche. Y las sombras. El eco de las sombras" (235).

\section{CUERPO, SEXUALIDAD Y DESEO}

La intensidad fantasmagórica de los cuerpos espectrales que pueblan Comala contrasta con la intensidad erótica que Susana San Juan expresa; se trata de una conjunción explosiva e inesperada, pero al mismo tiempo prefigurada por las condiciones de desnudez y locura que hemos señalado; desafío y resistencia son el preludio de la fruición corporal esperada y, sin embargo, frustrada: "Y lo que yo quiero de él es su cuerpo. Desnudo y caliente de amor; hirviendo de deseos; estrujando el temblor de mis senos y de mis brazos. Mi cuerpo transparente suspendido del suyo. Mi cuerpo liviano sostenido y suelto a sus fuerzas" (288); y luego: "Tengo la boca llena de ti, de tu boca. Tus labios apretados, duros como si mordieran oprimidos mis labios..." (300).

Es a consecuencia del cuerpo frustrado, de la pasión sin destino, del amor no realizado, que Susana San Juan flagela su cuerpo: "El padre Rentería la dejó acercarse a él; la miró cercar con sus manos la vela encendida y luego juntar su cara al pabilo inflamado, hasta que el olor a carne chamuscada lo obligó a sacudirla, apagándola de un soplo" (280). En este poderoso gesto simbólico, Susana intenta quemar todo lo que es pasión de su cuerpo, desesperanza del amor incompleto: "¿Qué haré ahora con mis labios sin su boca para llenarlos? ¿Qué haré de mis adoloridos labios?” (288).

Es esa "carne chamuscada" la que hace contrapeso a la carne gozosa que Susana recuerda:

Que dormía acurrucada, metiéndose dentro de él, perdida en la nada al sentir que se quebraba su carne, que se abría como un surco abierto por un clavo ardoroso, luego tibio, luego dulce, dando golpes duros contra su carne blanda; sumiéndose, sumiéndose más, hasta el gemido (287).

Así, mientras Susana San Juan ofrece su carne a Florencio, Pedro Páramo, por su lado, busca en otras mujeres la carne que ella le niega:

Pensó en Susana San Juan. Pensó en la muchachita con la que acababa de dormir apenas un rato. Aquel pequeño cuerpo azorado y tembloroso que parecía iba a echar fuera su corazón por la boca. "Puñadito de 
carne", le dijo. Y se había abrazado a ella tratando de convertirla en la carne de Susana San Juan (295, subrayado nuestro).

En esos imaginarios corporales, cuerpo y carne articulan esa dialéctica entre vida y muerte, entre cuerpo y alma, entre goce y flagelación, entre silencios $\mathrm{y}$ voces, lo que transforma a Comala en una enorme metáfora del universo cultural mexicano, en el cual, como dice Paz:

El desprecio a la muerte no está reñido con el culto que le profesamos. Ella está presente en nuestras fiestas, en nuestros juegos, en nuestros pensamientos. Morir y matar son ideas que pocas veces nos abandonan. La muerte nos seduce. La fascinación que ejerce sobre nosotros quizá brote de nuestro hermetismo y de la furia con que lo rompemos (63).

Pero también el cuerpo es parte de una visión cósmica, particular y universal, donde el tiempo es, simultáneamente, cotidiano y universal. Como dice Saldías, "El cuerpo es entonces materia condenada a recordar durante toda la eternidad: materia consciente, carne recordada y que recuerda, y por tanto condenada a una conciencia eterna y dolorosa del pasado" (30). En efecto, en Pedro Páramo, así como hay una muerte física y una muerte cósmica también hay un cuerpo físico y un cuerpo cósmico; uno y otro se retroalimentan para crear un espacio de intersección, donde la vida es un accidente de la muerte y no al revés, y donde los cuerpos son accidentes de las almas.

\section{TIEMPO, ESPACIOS Y CORPORALIDADES}

El reloj de la iglesia dio las horas, una tras otra, una tras otra, como si se hubiera encogido el tiempo.

Pedro Páramo (205)

La estructura temporal en Pedro Páramo es otro de los sostenes articulatorios del relato, y su descripción es inseparable de la inteligibilidad del texto. Se podría decir que su estructura elemental, de base, parte de una temporalidad vital y de una temporalidad mortuoria, dos modos del transcurrir que se solapan constantemente para crear una suerte de universo donde predomina, por paradójico que parezca, una eternidad vivida. A partir de ese fondo temporal, es posible buscar las articulaciones que Rulfo construye entre 
tiempos diversos. Para comenzar, es importante señalar que el texto usa la palabra "tiempo" 38 veces, además de términos de carácter temporal como "horas" (13 veces), "días" (21 veces), "noches" (11 veces). Visto el ambiente mortuorio de Comala, sorprende el predominio de los días sobre las noches. Así mismo, el texto utiliza los términos "ayer" (7 veces), "hoy" (10 veces), "mañana" (25 veces) o "pasado mañana" (3 veces), donde se observa un predominio absoluto de "mañana", lo que parecería articularse coherentemente con ese futuro indefinido de la muerte y de la eternidad, con ese no-tiempo irresuelto para los muertos condenados a observar, recordar y conversar sobre los sucesos de un pueblo donde la vida ya no existe; incluso, donde el prolífico dador de la vida, de la fecundación renovadora, decide expresamente dejar que Comala muera:

Porque fueron días grises, tristes para la Media Luna. Don Pedro no hablaba. No salía de su cuarto. Juró vengarse de Comala:

- Me cruzaré de brazos y Comala se morirá de hambre.

Y así lo hizo (303-304).

La propia Dolores sintetiza la relación entre el tiempo y la eternidad: "Sentirás que allí uno quisiera vivir para la eternidad. El amanecer, la mañana, el mediodía y la noche, siempre los mismos; pero con la diferencia del aire" (246).

Para nosotros, en el marco de esas dos temporalidades, vital y mortuoria, hay tres tipos de subestructuras temporales que se expresan a lo largo de la novela. Por un lado, hay un tiempo cronológico que se manifiesta en expresiones como "Entonces hasta dentro de ocho días, señores", "A los tres días todos estaban sordos", "me durará mis tres días", "en el trabajo y cuidados que libras todos los días", etc. Allí el tiempo recupera la noción de sucesión y de duratividad. El segundo tipo lo denominamos tiempo estacional, pues se refiere al tiempo como ciclo climático y se manifiesta en expresiones como "Allá afuera debe estar variando el tiempo", "tiempo de aguas", "ese tiempo de la canícula", etc. Como se ve, en este tipo de tiempo se privilegia la repetición periódica propia del ciclo. El tercer tipo de tiempo lo hemos denominado tiempo de época y, a diferencia de los anteriores, enfatiza un período específico, no repetitivo, que marca la historia personal o colectiva de los actores. El tiempo de época se manifiesta, por ejemplo, en expresiones como "días de duelo", "fueron días grises, tristes para la Media Luna", "para estos días", etc. Se trata de períodos generales de tiempo, sin límites específicos, pero que marcan etapas en la vida de quienes los recuerdan y, por lo tanto, ocupan espacios significativos en la memoria de personas y colectivos. 
Sin embargo, esos tres tiempos se articulan y rearticulan en la estructura temporal general de la novela que juega con avances y retrocesos que subvierten la linealidad narrativa, pues no hay sucesión sino avances y retrocesos, presentes y pasados que, no obstante, buscan construir un sentido de simultaneidad, lo que sorprende a algunos lectores desprevenidos. Se trata de un recurso en el que Rulfo abandona la linealidad narrativa tradicional, para mostrar la simultaneidad de hechos que configuran el universo cósmico, el tiempo de la eternidad, donde no existe sucesión; es ese universo el que Comala encarna. Dolores Preciado describe ese no-tiempo narrativo de la siguiente manera:

Sentirás que allí uno quisiera vivir para la eternidad. El amanecer; la mañana; el mediodía y la noche, siempre los mismos; pero con la diferencia del aire. Allí, donde el aire cambia el color de las cosas; donde se ventila la vida como si fuera un murmullo; como si fuera un puro murmullo de la vida... (246).

Ello explica por qué hay solo dos fechas relativamente precisas: 8 de abril, día fijado para el matrimonio entre Pedro Páramo y Dolores Preciado; y 8 de diciembre, día que muere Susana San Juan. Luego aparecen otras marcas temporales como las de los tres meses explícitamente nombrados: febrero, "cuando las mañanas estaban llenas de viento"; agosto como el "tiempo de canícula"; y octubre, tiempo de las cosechas.

Ahora bien, ¿cómo se asocian cuerpo y tiempo en la novela? ¿De qué manera la estructura temporal se proyecta sobre los imaginarios corporales o, a la inversa, cómo estos actualizan las diversas formas del tiempo? Uno de los párrafos articuladores de esa relación entre cuerpo y tiempo es aquel donde la madre de Pedro Páramo le informa que su padre, Lucas Páramo, ha muerto:

Y aquí, aquella mujer, de pie en el umbral; su cuerpo impidiendo la llegada del día; dejando asomar, a través de sus brazos, retazos de cielo, y debajo de sus pies regueros de luz; una luz asperjada como si el suelo debajo de ella estuviera anegado en lágrimas. Y después el sollozo. Otra vez el llanto suave pero agudo, y la pena haciendo retorcer su cuerpo (214).

Esa organización de las relaciones entre estructura corporal y temporal se observa también cuando Juan Preciado escucha los gritos de alguien a quien estarían asesinando; será Damiana quien le cuente que son los ecos del tiempo en que Toribio Alderete fue ahorcado: "Tal vez sea algún eco 
que está aquí encerrado. En este cuarto ahorcaron a Toribio Aldrete hace mucho tiempo. Luego condenaron la puerta, hasta que él se secara; para que su cuerpo no encontrara reposo" (222). Lo mismo ocurre con Susana San Juan: "Entonces su cuerpo se quedó desnudo, refrescado por el viento de la madrugada". También el amanecer es prefigurado en el cuerpo de Pedro Páramo: "Pedro Páramo siguió moviendo los labios, susurrando palabras. Después cerró la boca y entreabrió los ojos, en los que se reflejó la débil claridad del amanecer" (305).

Esa simbiosis entre cuerpo y tiempo es también un dispositivo que le permite a la novela desarrollar una fusión entre cuerpo y ambiente, de modo que uno y otro se acoplen a los imaginarios de la muerte y del morir, un proceso que realiza el tránsito entre la vida que las primeras páginas nos presentan y la muerte total y absoluta que, en fin de cuentas, es Comala. Se trata de un proceso general de coalescencia simbólica, en el que se mezclan y confunden imaginarios vitales y mortuorios, corporales y ambientales, voces y silencios, para crear, con una eficacia narrativa extraordinaria, ese universo de Comala donde la muerte es la presencia viva de unas vidas frustradas y aniquiladas.

\section{CUERPO, PIEL Y PECADO...}

Al hablar sobre la espectralidad corporal de los personajes, Maldonado, desde una perspectiva lacaniana, señala que "Comala es el mundo de los cuerpos sin órganos: de oídos sordos como los de Abundio, de los 'ojos tan sin mirada' de Dorotea y de 'voces ya desgastadas por el uso"' (53); y agrega que el pecado, como se observa en el caso de los hermanos incestuosos, es parte del espacio interior del cuerpo o del alma, pero también de su espacio exterior, de la piel, donde las faltas aparecen como manchas visibles, tal como lo expresa la hermana de Dondis: "—¿No me ve el pecado? ¿No ve esas manchas moradas como de pote que me llenan de arriba abajo? Y eso es sólo por fuera; por dentro estoy hecha un mar de lodo" (239).

Esta noción de cuerpo espectral se asemeja a la noción de cuerpo fantasmal señalada por Boullosa, y evidencia ese carácter sombrío, etéreo y evanescente de la corporalidad de los personajes de Pedro Páramo, una corporalidad que encaja con el marco de esa hiperisotopía de la muerte a la que nos hemos referido antes, y dentro de cuyos límites se desarrollan varias entradas temáticas. Pero esos cuerpos espectrales, que se expresan en voces y ruidos del silencio, son también expresivos de deseos no consumados y 
por tanto frustrados, así como de pecados que condenan a una muerte sin redención alguna.

Esa rebelión callada y ese desafío corporal femenino ${ }^{6}$, particularmente notorio en Susana, aparece también, aunque con menor intensidad, en Eduviges Dyada, quien, a petición de su amiga Dolores Preciado, tal como le cuenta al propio Juan Preciado, la sustituye en la cama el día de su matrimonio con Pedro Páramo: "Me valí de la oscuridad y de otra cosa que ella (Dolores) no sabía: y es que a mí también me gustaba Pedro Páramo. Me acosté con él, con gusto, con ganas. Me atrinchilé a su cuerpo" (207). Ese mismo deseo erótico y sexual Rulfo lo describe también en las sesiones de cura que Inocencio Osorio, El Perico, practica sobre Eduviges:

Y a tu madre la enredó como lo hacía con muchas. Entre otras, conmigo. Una vez que me sentí enferma se presentó y me dijo: “Te vengo a pulsear para que te alivies". Y todo aquello consistía en que se soltaba sobándola a una, primero en las yemas de los dedos, luego restregando las manos; después los brazos, y acababa metiéndose con las piernas de una, en frío, así que aquello al cabo de un rato producía calentura. Y mientras maniobraba, te hablaba de tu futuro... A veces se quedaba en cueros porque decía que ese era nuestro deseo. Y a veces le atinaba; picaba por tantos lados que con alguno tenía que dar (206-207).

Por último, la novela asocia también la noción de cuerpo a la tierra; se trata, como señala Saldías, de una asociación que hace del primero una representación pecaminosa, literalmente expresada con el término "lodo", cuando se habla de la hermana incestuosa de Donis: "El cuerpo de aquella mujer hecho de tierra, envuelto en costras de tierra, se desbarataba como si estuviera derritiéndose en un charco de lodo". Esa representación de un cuerpo telúrico pecaminoso se extiende a otros personajes sumidos en una

6 Aguirre Barrera ha realizado una investigación sobre la sexualidad femenina en seis mujeres en Pedro Páramo. Lamentablemente no incluye a Susana San Juan, el personaje fundamental en la realización femenina en la novela. La autora concluye que "sólo la madre del cacique y Dolores fungen al mismo tiempo como esposas y madres biológicas socialmente legítimas. Los otros cuatro personajes quebrantan el orden social, en el sentido de que no se ajustan al canon femenino que impone ambos roles en la mujer cuyo estatuto social es considerado positivo, transgresión que resulta en una valoración negativa de estas mujeres" (267). 
purgación eterna de sus pecados, lo que lleva a Saldías a afirmar que "[e]1 cuerpo es entonces materia condenada a recordar durante toda la eternidad: materia consciente, carne recordada y que recuerda, y por tanto condenada a una conciencia eterna y dolorosa del pasado" (30).

Ahora bien, si hemos señalado fragmentos, palabras, frases en esta búsqueda de una isotopía de la mirada, de una hiperisotopía corporal y de los imaginarios corpo-mortales, es, a fin de cuentas, en la totalidad del texto donde se percibe mejor el sentido de la novela, un sentido que se dibuja desde el inicio con la muerte de Dolores Preciado, y se confirma al final con la muerte de Pedro Páramo. Como en un círculo de sentido, ambas muertes son descritas con énfasis corporal; en efecto, mientras la muerte de la primera se expresa en "sus manos muertas", la del segundo se expresa en un cuerpo que en su último latido se va "desmoronando como si fuera un montón de piedras".

En medio de ese ciclo mortuorio, entre su inicio y su cierre, Comala se va poblando de muertos que no hablan sino susurran, que han perdido sus vidas en los silencios de sus propios cuerpos, prisioneros, sin esperanza alguna, en la eternidad del purgatorio.

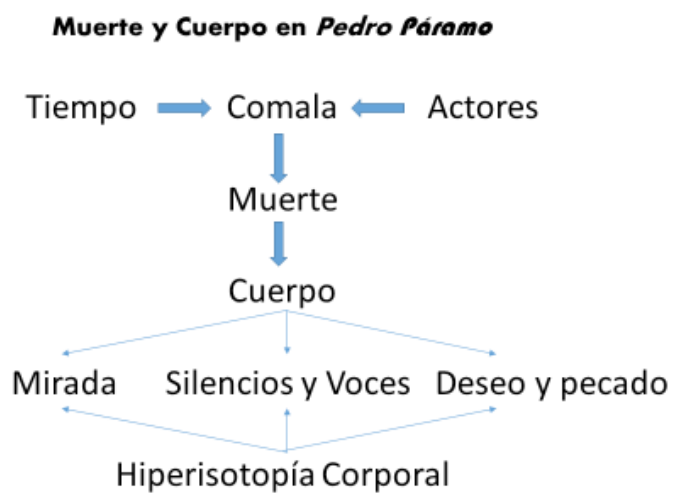

Como puede verse en el esquema anterior, los grandes temas de la novela se articulan, en nuestra opinión, a dos hiperisotopías principales: muerte y cuerpo, integradas ambas por isotopías menores, que orientan la lectura del texto. Si bien es cierto que sería erróneo restringir el universo semántico de Pedro Páramo a solo esas dos hiperisotopías, no es menos cierto que ellas constituyen pilares fundamentales de la estructura narrativa; ellas 
se ramifican y entrecruzan con los varios temas del universo creado por Rulfo entre espacios, actores y tiempos de una gran riqueza imaginativa. Es justamente esa riqueza la que ha conducido a una innumerable cantidad de análisis e interpretaciones. Muchas de ellas, sin embargo, necesariamente pasan, aunque sea brevemente, por las significaciones que los cuerpos y sus imaginarios proyectan en la narración.

\section{CONCLUSIONES: LA METÁFORA CORPORAL}

Hemos visto con Boullosa (1998) que la corporeidad en Pedro Páramo tiene un carácter fantasmal, y hemos visto que, siguiendo nuestra hipótesis interpretativa, la novela construye imaginarios corporales que permean toda la narración, marcan a sus actores y a las estructuras temporales que hemos descrito. Si, como varios autores han señalado, el tema de la muerte estructura de manera decisiva toda la novela - "todo consiste en morir", dice Eduviges Dyada-, lo que la ata inseparablemente a la cultura de la muerte en México, que le sirve de macro contexto general, también el tema del cuerpo es un componente categórico que apuntala, justamente, al de la muerte. Esa relación dialéctica cuerpo $\rightarrow$ muerte $\rightarrow$ cuerpo fecunda un sentido global, donde metáfora de la muerte y metáfora del cuerpo vienen a reconciliarse en una visión general que, desde el contexto mexicano, se universaliza; de modo que lectores pertenecientes a contextos históricos y culturales distintos encuentran en la novela sentidos con los que pueden relacionarse sin mayores conflictos.

Esa metáfora corporal, expresada en ojos que pueblan y cimientan una poderosa semiótica de la mirada, en deseos corporales insatisfechos, en voces que configuran una semiótica del silencio, formula un dinámico sentido de la corporeidad como componente de los personajes, pero que también permea los espacios y los tiempos, y que, finalmente, crea un universo único, el universo de Comala.

\section{BIBLIOGRAFÍA}

Aguirre Barrera, Dulce. "Esposas y madres: la sexualidad femenina en Pedro Páramo". Revista de Estudios de Género. La ventana, No. 28 / 2008. http://www.scielo.org.mx/ scielo.php?script $=$ sci_arttext\&pid=S1405-94362008000200010 
Battersby, Eileen. "The dead among the living: Pedro Páramo". Irish Times. Sat, Sep 13, 2014. https://www.irishtimes.com/culture/books/the-dead-among-the-living-pedrop\%C3\%A1ramo-1.1926754

Bellini, Giuseppe. "Función del silencio en «Pedro Páramo»”. Cervantes Virtual. http://www. cervantesvirtual.com/obra-visor/funcion-del-silencio-en-pedro-paramo--0/html/837e $8 \mathrm{~d} 3 \mathrm{f}$ 00cb-4660-aae0-119aecf3a085_6.html Enero 2018.

Boullosa, Carmen. "En nombre del Padre, del Hijo y de los Fantasmas". Revista Canadiense de Estudios Hispánicos. 2:2 (1998): 295-305. http://www.revistadelauniversidad.unam. mx/ojs_rum/files/journals/1/articles/14564/public/14564-19962-1-PB.pdf

Carvalho da Silva, Simone Andrea. "Muerte y religiosidad en Pedro Páramo". juan-rulfo. com. http://juan-rulfo.com/pedro_paramo.pdf. Enero 2018.

Domínguez, Silvya M. "La Comala de Juan Rulfo: una distopía”. Acequias 19 (2003): 62-67.

Echavarren, Roberto. "Pedro Páramo: la muerte del narrador". Inti: Revista de literatura hispánica, No. 13. Primavera-Otoño 1981. https://digitalcommons.providence.edu/inti/ vol1/iss $13 / 14$

Eco, Umberto. Semiotics and the Philosophy of Language. Bloomington: Indiana University Press. 1984.

Ekstrom, Margaret V. “Introduction to Rulfo's Naming Techniques In Pedro Paramo”. Literary Onomastics Studies, Vol. 6, 1979. http://digitalcommons.brockport.edu/los/vol6/iss1/5. 1979.

Finol, José Enrique. Análisis de una caricatura de Roque Maldonado. En diario El Comercio. (11/08/2015). Quito, Ecuador. Inédito. 2015.

Finol, José Enrique y David Enrique Finol. "De la Mitología a la Neo-Mitología: el Minotauro y sus laberintos en tres textos". Revista de Literatura Hispanoamericana 66 (2014): 11-31.

“Texto, interpretabilidad e interpretación: límites y alcances". Chasqui. Revista Latinoamericana de Comunicación 135 (2017): 217-232.

Freeman, George R. "La caída de la Gracia: clave arquetípica de Pedro Páramo". En Claude Fell (Coord.). Juan Rulfo. Toda la obra. Madrid: Colección Archivos (1992): 741-744.

García Fierro, Covadonga. "La filosofía de la muerte en Pedro Páramo". Fogal 14. 2014. https://www.revistafogal.com/2014/09/15/la-filosof\%C3\%ADa-de-la-muerte-en-pedrop\%C3\%A1ramo/ Noviembre-Enero, 2017-2018.

García Gutiérrez, Rosa. "El cuerpo mítico y el cuerpo carnal de Susana San Juan”. Monteagudo, 3. "Época 22 (2017): 97-116.

Greimas, Algirdas-Julien y Joseph Courtés. Sémiotique. Dictionnaire raisonné de la théorie du langage. París: Hachette Université, 1979.

Hannan, Annika. "A subject of desire: sexuality, creation and the (Maternal) individual in Juan Rulfo`s Pedro Páramo". Revista de Estudios Hispanicos. Oct 1999, Vol. 33 Issue 3: 441-472.

Kent, Lioret. "A matter of life and death in 'Pedro Páramo"”. Romance Notes, Vol. 17, No. 1 (1976): 99-102.

Klinkenberg, Jean-Marie. Manual de Semiótica General. Bogotá: Universidad de Bogotá "Jorge Tadeo Lozano", 2006. 
Maldonado, Luis. “Deseo, cuerpo y desintegración en Pedro Páramo". Inti: Revista de literatura hispánica 54, Article 4, 2001. http://digitalcommons.providence.edu/inti/vol1/iss54/4

Matos Frias, Joana. "Receita contra o tédio da retina: o cine-olhar de Cinatti". Aula de los medios. P. Serra Editor. Madrid: Ediciones Universidad de Salamanca, 2012.

Maya Franco, Claudia María. "La muerte, el poder y el amor. Pedro Páramo y el discurso como acontecimiento". Escritos / Medellín - Colombia. Vol. 20, N. 45 (2012): pp. 435 453. julio-diciembre 2012.

Morales Ladrón, Marisol. "Vida, muerte y parálisis en Pedro Páramo, de Juan Rulfo, y 'The dead' de James Joyce”. Exemplaria. Vol. 3. 1999.

Origoni, Yannella. "Pedro Páramo: la muerte, la mitología y su relación con la cultura mexicana". Universia, 03 de noviembre de 2015. http://noticias.universia.net.mx/portada/ noticia/2015/11/03/1133107/pedro-paramo-muerte-mitologia-relacion-cultura-mexicana.html

Patron, Sylvie. "La mort du narrateur et l'interprétation du roman. L'exemple de Pedro Páramo de Juan Rulfo". Théorie, analyse, interprétation des récits / Theory, analyses, interpretation of narratives, Berne, Peter Lang (2011): 147-182. <hal-00698701>

Paz, Octavio. El laberinto de la soledad. México: Fondo de Cultura Económica, 1994 [1950].

Polisena, Araceli Noelia. "Muerte, poder y humor en Pedro Páramo de Juan Rulfo". Topologik, $21 / 2017 . \mathrm{http} / /$ www.topologik.net/Araceli_Noelia_Polisena_Issue_21.pdf

Ruffinelli, Jorge. "Prólogo". Juan Rulfo. Obra completa. Caracas: Biblioteca Ayacucho. Vol. XIII. 1977.

Rulfo, Juan. Juan Rulfo. Obras. Barcelona: Editorial RM - Fundación Juan Rulfo, 2014.

Obra completa. Caracas: Biblioteca Ayacucho. Vol XIII, 1977.

Saldías, Mónica. La carne recordada. Un análisis de la atemporalidad mítica y la subversión religiosa en Pedro Páramo, 2011. Thesis degree of Bachelor. Dalarna University. http:// www.diva-portal.org/smash/record.jsf?pid=diva2\%3A519113\&dswid $=8773$

Sontag, Susan. Prólogo a Pedro Páramo. Segunda traducción al inglés realizada por Margaret Sayers Peden. En Juan Rulfo. Obras. México: Editorial RM \& Fundación Juan Rulfo, 2014.

Xie, Gus. “If Death Ever Had a Voice': Narrative Fragmentation in Pedro Páramo”. Particle. UNMC Literary Magazine. No. 2015. http://particle.sanottingham.org/if-death-ever-hada-voice-narrative-fragmentation-in-pedro-paramo/ 